\title{
Evaluation of congestive heart failure in children with rheumatic heart disease as a criterion of rheumatic activity
}

\author{
Z. H. ABDIN AND M. A. M. ABUL-FADL \\ From the Pyramid Rheumatic Heart Centre, Giza, U.A.R.
}

The onset of congestive heart failure (CHF) in a child with rheumatic heart disease has generally been taken to indicate the presence of active carditis (Wilson, 1940; Nadas and Hauck, 1960). This has been thought to be the case even in patients with a normal erythrocyte sedimentation rate (ESR), which might be attributed to an associated disturbance of liver function (Payne and Schlesinger, 1935; Wood, 1936; Schlesinger, 1946; Harris, Friedman, and Tang, 1957). Nevertheless, Parry (1961) and Taranta, Spagnuolo, and Feinstein (1962) demonstrated that CHF associated with rheumatic activity usually causes elevation of the ESR.

Spagnuolo and Feinstein (1964), however, studied children with $\mathrm{CHF}$ associated with rheumatic heart disease and concluded that heart failure in children, as in adults, could often be attributed to mechanical causes, atrial fibrillation, or drug toxicity, rather than to active rheumatic carditis. No further studies on the problem have since been carried out, and it thus seemed desirable to investigate the question in our centre, where there is an ample supply of clinical material.

\section{Materials and methods}

A series of 418 children suffering from rheumatic heart disease and aged between 6 and 14 years formed the subject of this study. They were divided into two groups: a study group (S) given benzathine penicillin prophylaxis and a control group (C) given injections of sterile water.

The two groups ( $\mathrm{S}$ and $\mathrm{C}$ ) were selected on a random basis, carefully matched with regard to age, sex, and severity of cardiac involvement. During the early stages of the study, however, it was thought advisable to transfer twelve young children with severe heart disease from the control to the study group, so that they should receive much-needed therapy. The study group thus numbered 221 and the control group 197 cases.

The study was conducted for 3 years. All patients were encouraged to attend our outpatient clinic regularly, where they underwent periodical clinical and laboratory examination and received monthly injections. Laboratory tests included the determination of the ESR (Wintrobe, 1961), the blood serum antistreptolysin-O titre (ASOT) (Rantz and Randall, 1945), and throat swabs for identification of group A beta-haemolytic streptococci. Radiographs of the chest and electrocardiograms were taken yearly and whenever thought desirable.

For the first 18 months the study group received a monthly intramuscular injection of Depot V Biotic, $1,200,000$ units. When its potency was assessed it proved to be equivalent to only 900,000 units of benzathine penicillin, and Penadur $(1,200,000$ units) was therefore used in place of the Depot $\mathrm{V}$ for the next 18 months of the study. A urine test for penicillin using the lutea sarcinata cultures (Markowitz and Gordis, 1968) was done from time to time before the next injection of Penadur to ensure a penicillin action althrough the month.

The onset of CHF was carefully noted. Diagnosis was: based on classical signs and symptoms, i.e. dyspnoea, palpitations, enlargement of the liver, and raised venous pressure with or without oedema of the lower limbs. Children who developed heart failure were carefully studied with regard to the effect of chemoprophylaxis, and the correlation of CHF with ASOT levels, ESR, and other major and minor criteria of rheumatic activity (Duckett Jones, 1944).

\section{Results}

Tables I and II show the effect of chemoprophylaxis on the incidence of congestive heart failure.

Table I Comparative incidence of $C H F$ in $C$ and $S$ groups, when the latter received Depot $V$ prophylaxis January 1,1967 , to July 1,1968

\begin{tabular}{|c|c|c|c|c|}
\hline \multirow[t]{2}{*}{ Group } & \multirow{2}{*}{$\begin{array}{l}\text { Average no. } \\
\text { of attend- } \\
\text { ances }\end{array}$} & \multirow{2}{*}{$\begin{array}{l}\text { Patient- } \\
\text { months }\end{array}$} & \multicolumn{2}{|c|}{ Congestive heart failure } \\
\hline & & & No. & Per cent. \\
\hline C & $\begin{array}{l}197 \\
221\end{array}$ & $\begin{array}{l}3,546 \\
3,978\end{array}$ & $\begin{array}{l}35 \\
40\end{array}$ & $\begin{array}{l}18 \cdot 0 \\
18 \cdot 0\end{array}$ \\
\hline Total & 418 & 7,524 & 75 & $18 \cdot 0$ \\
\hline
\end{tabular}


Table II CHF in $C$ and $S$ groups, when the latter received Penadur prophylaxis

July 1, 1968, to December 30, 1969

\begin{tabular}{|c|c|c|c|c|}
\hline \multirow[t]{2}{*}{ Group } & \multirow{2}{*}{$\begin{array}{l}\text { Average no. } \\
\text { of attend- } \\
\text { ances }\end{array}$} & \multirow{2}{*}{$\begin{array}{l}\text { Patient- } \\
\text { months }\end{array}$} & \multicolumn{2}{|c|}{ Congestive heart failure } \\
\hline & & & No. & Per cent. \\
\hline $\begin{array}{l}\mathrm{C} \\
\mathrm{S}\end{array}$ & $\begin{array}{l}168 \\
199\end{array}$ & $\begin{array}{l}3,024 \\
3,562\end{array}$ & $\begin{array}{r}17 \\
8\end{array}$ & $\begin{array}{r}10 \cdot 0 \\
4.0\end{array}$ \\
\hline Total & 367 & 6,586 & 25 & 6.8 \\
\hline
\end{tabular}

The incidence of CHF became lower in the study group than in the control group during the second 18 months, suggesting that CHF may well be related to the occurrence of active rheumatic carditis. The general incidence of $\mathrm{CHF}$ declined during the second phase of the investigation, owing perhaps to more regular attendance and early treatment of suspected activity.

Thirty-nine cases with CHF, who had been under close supervision and who had had repeated ASOT determinations for at least 4 months before the onset of heart failure, were analysed with relation to their ASOT levels coincident with or just before the onset of heart failure. The results are shown in Table III.

Table III Incidence of active disease as judged by ASO titres in 39 children with $\mathrm{CHF}$

\begin{tabular}{|c|c|c|c|}
\hline \multirow[t]{2}{*}{$A S O T$} & \multicolumn{2}{|c|}{ Patients } & \multirow[t]{2}{*}{ No. of tests } \\
\hline & No. & Per cent. & \\
\hline $\begin{array}{l}\text { Positive } \\
\text { Negative }\end{array}$ & $\begin{array}{r}33 \\
6\end{array}$ & $\begin{array}{l}84 \\
16\end{array}$ & $\begin{array}{l}530 \\
140\end{array}$ \\
\hline Total & 39 & 100 & 634 \\
\hline
\end{tabular}

Over 80 per cent. of cases with recent CHF had coincident elevation of the ASOT by two or more dilutions above basal values as previously determined, or had an ASOT of 333 units or above, our normal basal value for children being 100 or below (Abdin, 1971). Though other studies (Abdin and Abul-Fadl, 1971) have illustrated the high prevalence of streptococcal infection among Egyptian children, an incidence of over 80 per cent. is far more than can be expected to occur in the course of about 2 months. The occurrence of streptococcal infection cannot be per se the direct cause of CHF, and active carditis is presumably the only possible predisposing factor for the CHF for these cases with an elevated ASOT.

The relation of CHF (with positive ASOT) to Jones's criteria has also been analysed; the data are set out in Table IV.

\section{Discussion}

Knowledge about the causes of heart failure in these patients is not only of academic interest but also of
Table IV Relation of $\mathrm{CHF}$ with elevated ASOT to Jones's major and minor criteria

\begin{tabular}{|c|c|c|}
\hline Criteria & No. & Per cent. \\
\hline $\begin{array}{l}\text { Major } \\
\text { Arthritis } \\
\text { Pericarditis } \\
\text { Chorea } \\
\text { Rheumatic nodules } \\
\text { Erythema marginatum } \\
\text { Nil }\end{array}$ & $\begin{array}{r}7 \\
2 \\
1 \\
1 \\
0 \\
24\end{array}$ & $\begin{array}{r}22 \cdot 0 \\
6 \cdot 0 \\
3 \cdot 0 \\
3 \cdot 0 \\
0 \\
66 \cdot 0\end{array}$ \\
\hline $\begin{array}{l}\text { Minor } \\
\text { Pallor } \\
\text { Arthralgia } \\
\text { Raised ESR } \\
\text { Epistaxis } \\
\text { Fever } \\
\text { Electrocardiogram changes } \\
\text { Nil }\end{array}$ & $\begin{array}{r}26 \\
22 \\
28 \\
11 \\
12 \\
6 \\
5\end{array}$ & $\begin{array}{l}78 \cdot 7 \\
66 \cdot 6 \\
84 \cdot 0 \\
33 \cdot 3 \\
36 \cdot 3 \\
18 \cdot 2 \\
15 \cdot 2\end{array}$ \\
\hline
\end{tabular}

practical importance. Suppressive treatment of an inflammatory lesion in the heart may help to relieve heart failure and may thus contribute to prolonging life. The clinical diagnosis of disease activity is, however, by no means always easy.

For many years there was a tendency to accept the onset of CHF in a rheumatic child as evidence of an active rheumatic process in the heart, although proof for this assumption was lacking. Nadas and Hauck (1960) wrote: 'The axiom, the origin of which is hard to trace, is that a child with CHF on a rheumatic basis always has active carditis.'

Spagnuolo and Feinstein (1964) questioned this axiom, pointing out that it did not seem to rest on firm evidence. They further concluded that many of the heart failure episodes in rheumatic children are actually mechanical, the result of atrial fibrillation, drug toxicity, etc.

The data obtained in our present study, however, seem to support the older views. Elevation of the ASOT at the onset of an attack of heart failure occurring in 84 per cent. of young children is strongly indicative of a recent streptococcal infection which has presumably brought about active disease in the heart (rheumatic activity) and heart failure.

Though atrial fibrillation (perhaps related in part to digitalis intolerance on the part of the inflamed myocardium) may have contributed to heart failure, careful interrogation of patients yielded a history of arthritis or arthralgia some time before the onset of heart failure, or an elevated ASOT 1 or 2 months previously.

An elevated ESR is difficult to assess among our cases because of the general prevalence of high ESRs among our rheumatic children, even among those with no concomitant active disease (Abdin and Abul-Fadl, 1971). Nevertheless, our observations indicate that a major rise in ESR was rather frequent 
with cases of CHF. However, the ESR was sometimes seen to be quite low at the onset of severe CHF with huge liver enlargement, and was observed to rise later to high levels when the failure improved. We cannot therefore use the level of ESR to exclude, or to confirm, active disease in such cases, especially if the rise is not large (Abdin and Abul-Fadl, 1971).

In view of our present results we are inclined to consider a recent onset of CHF in a rheumatic child of 13 years or below, who had been free from signs of heart failure for a year or more, as evidence of active carditis, and to treat it on this basis using suppressive antirheumatic treatment. Chronic heart failure can, however, be treated differently, being managed largely with anti-failure measures.

\section{Summary}

In a follow-up study of 418 children with rheumatic heart disease, the incidence of congestive heart failure was lower in a group treated with chemoprophylaxis than in a control group. Over 80 per cent. of cases developing heart failure were shown to have an elevated antistreptolysin-O titre at or shortly before the time of failure. It is concluded that congestive heart failure in these circumstances indicates the presence of active rheumatic carditis and should be treated accordingly.

\section{References}

AbDin, Z. H. (1971) Sudan med. J., in press. Special Edition: Pediatric Symposium of the Sudan Assoc. of Pediatricians. (Spotlights on rheumatic fever in Egypt)

- and Abul-Fadl, M. A. M. (1971) Med. J. Cairo Univ., 34, 17 (Effect of subclinical streptococcal infections and certain parasitic infestations on the blood erythrocyte sedimentation rate)

Harris, T. N., Friedman, S., AND TANG, J. (1957) Amer. J. Med. Sci., 234, 259 (Paradoxical values of the erythrocyte sedimentation rate in rheumatic fever. A comparison among three acute phase tests)

JONES, T. DuCKeTt (1944) J. Amer. med. Ass., 126, 481 (Diagnosis of rheumatic fever)

MARKowITZ, M., AND GoRDIs, L. (1968) Pediatrics, 41, 151 (A mail-in technique for detecting penicillin in urine: Application to the study of maintenance of prophylaxis in rheumatic fever patients)

NadAS, A. S., AND HAUCK, A. J. (1960) Circulation, 21, 424 (Pediatric aspects of congestive heart failure)

Payne, W. W., ANd Schlesinger, B. (1935) Arch. Dis. Childh., 10, 403 (A study of the sedimentation rate in juvenile rheumatism)

PARRY, E. H. O. (1961) Acta med. scand., 169, 79 (Erythrocyte sedimentation rate in heart failure)

Rantz, L. A., ANd Randall, E. (1945) Proc. Soc. exp. Biol. (N.Y.), 59, 22 (Modification of the technic for determination of the antistreptolysin titer)

SCHLESINGER, B. (1946) Practitioner, 157, 38 (Blood sedimentation rate in rheumatic fever)

Spagnuolo, M., and Feinstein, A. R. (1964) Pediatrics, 33, 653 (Congestive heart failure and rheumatic activity in young patients with rheumatic heart disease)

Taranta, A., Spagnuolo, M., and Feinstein, A. R. (1962) Ann. intern. Med., 56, 367 ('Chronic' rheumatic fever)

Wirson, M. G. (1940) 'Rheumatic Fever. Studies of the Epidemiology, Manifestations, Diagnosis and Treatment of the Disease during the First Three Decades'. Oxford University Press, London

WinTrobe, M. M. (1961) 'Clinical Hematology', 5th ed. Lea and Febiger, Philadelphia

WooD, P. (1936) Quart. J. Med., n.s. 5, 1 (The erythrocyte sedimentation rate in diseases of the heart) 